\section{Integração européia e políticas de saúde: repercussões do mercado interno europeu no acesso aos serviços de saúde}

\author{
European integration and health policies: \\ repercussions of the internal European \\ Market on access to health services
}

Luisa Guimarães 1

Lígia Giovanella 2

\footnotetext{
1 Escola Nacional de Saúde Pública Sergio Arouca, Fundação Oswaldo Cruz, Rio de Janeiro, Brasil.

Correspondência L. Guimarães Escola Nacional de Saúde Pública Sergio Arouca, Fundação Oswaldo Cruz. Rua Leopoldo Bulhões 1480, Rio de Janeiro, $R J$ 21041-210, Brasil. luisa.guimaraes@solar.com.br
}

\begin{abstract}
This article explores the health policy repercussions of countries' regional integration into the European Union. The aim is to review the regulation of access in other countries, with the conclusion of the single European market and the free circulation of persons, services, goods, and capital. The article begins by reviewing the various forms of integration and describes the expansion and institutionalization of Community agencies. The repercussions of European integration on health policies and regulation of access are analyzed. Market impacts on health result from Treaty directives and internal policy adjustments to free circulation. Health services access is gradually regulated and granted by rulings. Projects along borders illustrate the dynamics where differences are used to achieve comprehensive care. In the oldest integration experience, the market regulation has generated intentional and non-intentional impacts on the health policies of member states, regardless of the organizational model. Knowledge and analysis of this experience signals challenges for the Southern Cone Common Market (Mercosur) and adds to future debates and decisions.
\end{abstract}

Economic Blocs; Health Policy; Border Health; European Union

\section{Introdução}

Processos de integração regional entre países para estabelecimento de relações econômicas e comerciais privilegiadas têm cada vez maior relevância política e sócio-econômica 1,2. Presentes em todos os continentes, acordos de integração e políticas bi e multilaterais encontram-se em estágios variados, têm distintas metas, marcos legais, mecanismos de implementação, controle e solução de conflitos 3,4. Operam transformações internas progressivas para capacitar países à abertura comercial mais ampla e buscam superar conflitos, aumentar segurança, aproveitar vantagens regionais de escala, melhorar eficiência e alcançar benefícios coletivos ${ }^{3}$. Nesse sentido, relacionam-se com fenômenos da globalização. Embora a inclusão de temas sociais nos acordos comerciais ainda seja tímida, observa-se influência destes sobre as políticas de saúde 2,5,6. Estudos da União Européia indicam que a integração repercutiu de modo intencional e não intencional nas políticas de saúde 7,8 .

No Brasil, a integração regional adquire elevada importância frente à extensa faixa fronteiriça 9. Seguindo tendência mundial de associação, o país integra o MERCOSUL cuja participação vem assumindo relevância na política externa brasileira 10 . O Brasil convive com fenômenos de intensificação do livre comércio que já apresentam reflexos sobre o setor saúde 11,12. 
Ao mesmo tempo, busca garantir o cumprimento dos princípios constitucionais do Sistema Único de Saúde (SUS), frente às realidades distintas e às dimensões continentais. Ainda que na atualidade o MERCOSUL se caracterize como união aduaneira - sistema de tarifas e cotas comuns nas relações comerciais externas -, os Estados-parte procuram constituir um mercado comum, com a livre circulação de pessoas, bens e serviços. Como mercado comum, integrando economias, o MERCOSUL tende a aproximar-se da modalidade de integração da União Européia 13,14,15. Desse modo, lições históricas da constituição e regulamentação da União Européia, por ser a mais antiga e profunda experiência, podem ilustrar a dinâmica de impactos da integração nas políticas de saúde e contribuir, assim, para o debate atual e decisões futuras com relação ao MERCOSUL.

O objetivo do presente artigo é explorar a conformação da União Européia e as repercussões sobre as políticas públicas e sistemas de serviços de saúde e verificar os processos de regulamentação do acesso aos serviços de saúde em outro país, com intuito de traçar paralelos com o MERCOSUL. O método utilizado foi revisão de literatura e documental. O presente texto fundamenta-se em estudo em desenvolvimento no Programa de Doutorado em Saúde Pública, na linha de pesquisa Políticas e Sistemas de Saúde em Perspectiva Comparada, na Escola Nacional de Saúde Pública Sergio Arouca, Fundação Oswaldo Cruz, Ministério da Saúde (ENSP/FIOCRUZ/MS).

$\mathrm{O}$ artigo está organizado em quatro tópicos principais. No primeiro, trata-se das características de processos de integração entre países indicando os diversos níveis de associação, seguido de aspectos históricos da constituição e do alargamento da União Européia e a conformação institucional comunitária. No segundo, analisa-se de que modo a temática da saúde é incorporada nos tratados da União Européia e quais as repercussões da regulamentação da livre circulação para o mercado único e sobre as políticas de saúde. No terceiro tópico, examina-se o acesso às ações e serviços de saúde transfronteiriços na União Européia, focalizando-se a regulamentação, a ampliação decorrente de jurisprudências da Corte de Justiça Européia e especificidades de regiões fronteiriças. Nas considerações finais são sintetizadas e analisadas questões da integração e as repercussões no acesso aos serviços de saúde no caso europeu, de modo a apontar no conhecimento da trajetória européia desafios a enfrentar no MERCOSUL.

\section{Processos de integração regional entre países e a conformação da União Européia}

\section{Modalidades de integração regional entre países}

Processos de integração regional entre países são, em geral, motivados por questões econômicas e geopolíticas e se realizam em ritmo mais veloz do que o desenvolvimento de mecanismos de harmonização social 14 . Acordos comerciais preferenciais estão muito difundidos entre países 3,4, e devido ao caráter econômico, processos de integração regional são regulados, no âmbito mundial, pela Organização Mundial do Comércio 2.

Acordos econômicos operam transformações progressivas internas nos países para capacitá-los à abertura comercial mais ampla 3 . Os processos de integração envolvem procedimentos de convergências, aproximações e harmonizações de políticas e de regulamentações que resultam em abolição de barreiras tarifárias legais e institucionais, facilitação do acesso às instituições comuns e permissão do consumo de serviços sociais em outros países. Logo, no campo social significam que direitos e garantias de cidadania ultrapassam os limites geográficos e legais das instituições e práticas de cada país e passam a ser compartilhados em todo o bloco. A integração não é, todavia, um fim em si mesma, é antes um processo em diversos domínios, com diferentes passos, multidimensional e com múltiplos níveis 16 .

Os objetivos dos acordos multilaterais firmados definem o grau da integração entre os países 4, o qual apresenta cinco estágios principais. O primeiro denomina-se área de livre comércio e caracteriza-se pela eliminação de tarifas alfandegárias e cotas entre os países membros. A união alfandegária, por sua vez, significa a adoção de sistema de tarifas e cotas comuns para relações comerciais externas. O mercado comum define-se pela eliminação de restrições de circulação de mercadorias, pessoas e capital. A união monetária decorre da harmonização e unificação de políticas e instituições econômicas. A confederação ou união política formaliza o mais profundo estágio de integração 13.

Os acordos comerciais influem nas políticas de saúde, entretanto, estudos indicam insuficiente coordenação intersetorial 2 e que falta explorar em profundidade as relações entre mercado e saúde 6 . A União Européia representa a modalidade mais profunda de integração entre países considerando o estágio dos acordos firmados, e demonstra capacidade de re- 
solver tensões derivadas de disparidades de desenvolvimento entre regiões e países. A experiência européia ilustra a adoção de fundos estruturais de desenvolvimento, que são necessários em processos de integração para reduzir desigualdades territoriais e sociais, as quais podem se configurar como barreiras não tarifárias à integração 17.

\section{Constituição, desenvolvimento}

\section{e alargamento da União Européia}

A União Européia vem se constituindo há mais de meio século, ao longo do qual incorporou novos Estados-Membros; em 2004, alcançou o centro e o leste europeu, o Mediterrâneo e o Mar Báltico, totalizando 25 países. Os acordos europeus constam de Tratados gradualmente revisados (Tabela 1). O início ocorreu nos anos 1950 quando seis países que na primeira e na segunda guerra mundiais tiveram posições antagônicas, acordaram questões de infra-estrutura energética, tendo o tema da promoção da paz como pano de fundo. Os primeiros acordos tinham por base o mercado de produtos e serviços, a facilitação alfandegária e políticas comuns de comércio e de agricultura. Nos anos 1970, foi criado o Fundo Europeu de Desenvolvimento Regional com recursos para executar políticas comuns nos campos social, regional e ambiental, e instituído o Sistema Monetário Europeu que passou a disciplinar as economias dos Estados-Membros. Nos anos 1980, novas adesões levaram à introdução de programas estruturais com objetivo de reduzir disparidades de desenvolvimento econômico entre a $E u$ ropa dos 1218 .

Nos anos 1990, foram firmados importantes Tratados: Maastrich, em 1992, e Amsterdã, em 1995. O Tratado de Maastrich - Tratado da União Européia - criou estruturas políticas e econômicas, previu a união monetária e a cidadania européia e instituiu políticas externa e de segurança comuns 18. Continha bases do mercado único europeu cuja regulamentação veio a ter impactos nos sistemas e serviços de saúde dos Estados-Membros 19,20,21. O Tratado de Amsterdã adaptou e reforçou o mercado único e a garantia da livre circulação de mercadorias, serviços, pessoas e capital. Em 2001, a Europa dos 15 assinou o Tratado de Nice, que alterou o funcionamento das instituições e critérios de votação. Em 2002, as moedas nacionais foram substituídas pela moeda única, o Euro. Em fins de 2004, a União Européia somou 25 Estados-Membros que juntamente com três países candidatos (Bulgária, Romênia e Turquia) assinaram o Tratado que instituiu uma Constituição para a Europa com previsão de entrada em vigor em dois anos, após referendo dos Estados-Membros 18.

A adesão gradual de países e a revisão incremental dos Tratados levaram à formulação de políticas públicas para além dos limites dos

Tabela 1

Cronologia da adesão de países e dos tratados da União Européia.

\begin{tabular}{ll}
\hline Ano & Adesão de Estados-Membros e assinatura de tratados \\
\hline 1951 & Alemanha, Bélgica, França, Itália, Luxemburgo e Holanda \\
1951 & Tratado da Comunidade Européia do Carvão e do Aço, entrada em vigor em 1952 (Paris) \\
1957 & Tratado da Comunidade Econômica Européia, entrada em vigor em 1958 (Roma) \\
1973 & Tratado da Comunidade Européia de Energia Atômica, entrada em vigor em 1958 (Roma) \\
1981 & Dinamarca, Irlanda e Reino Unido \\
1986 & Grécia \\
1986 & Espanha e Portugal \\
1992 & Ato Único Europeu, entrada em vigor em 1987 (Luxemburgo e Haia) \\
1995 & Tratado de Maastricht ou Tratado da União Européia, entrada em vigor em 1993 \\
1997 & Áustria, Finlândia e Suécia \\
2001 & Tratado de Amsterdã, entrada em vigor em 1999 \\
2002 & Tratado de Nice, entrada em vigor em 2003 \\
2004 & O Euro entra em circulação \\
2004 & Chipre, Eslováquia, Eslovênia, Estônia, Hungria, Letônia, Lituânia, Malta, Polônia e República Tcheca
\end{tabular}

Fonte: Elaborado com base nas informações contidas em dados da Comissão Européia 18. 
Estados-Nação. E para promover a coesão econômica e social européia, a integração impôs a implantação de esquemas institucionais supranacionais e mecanismos de redução de desigualdades territoriais e sociais.

Institucionalização e organismos comunitários da União Européia

Para efetivar os acordos europeus foram constituídos organismos que conformam espaço institucional supranacional de integração. $\mathrm{Na}$ União Européia, os arranjos institucionais realizados pressupõem ao mesmo tempo a migração de responsabilidades nacionais para aparato transnacional, a promoção de consensos e a superação de conflitos 22,23 . As instâncias supranacionais tratam de assuntos de políticas, de regulação e econômicos com delegação para decidir sobre questões de interesse comum e representar cidadãos, Estados-Membros e a União Européia. A instância decisória mais elevada é o Conselho Europeu integrado pelos Chefes dos Estados-Membros e pelo Presidente da Comissão Européia. A Comissão Européia é órgão executivo, defensor dos interesses comuns, integrado por membros indicados pelos países; zela pelo cumprimento do acordado e acompanha as decisões do Conselho de Ministros da União Européia. O Conselho de Ministros representa os governos nos debates comunitários. O Parlamento Europeu, formado por deputados eleitos nos países, exerce controle democrático 18.

Dois organismos completam as principais instituições comunitárias: um de controle financeiro e outro de defesa dos direitos comunitários. O Tribunal de Contas da União Européia, composto por indicados pelos EstadosMembros após consulta ao Parlamento Europeu, verifica a legalidade e regularidade de receitas e despesas da União Européia e a gestão financeira dos recursos comuns. A Corte de Justiça Européia, integrada por um juiz de cada Estado-Membro e advogados indicados de comum acordo, garante o cumprimento do direito comunitário mediante a interpretação e exame da aplicação dos Tratados. A existência de tal órgão único de decisão sobre a interpretação da legislação comunitária é garantia da aplicação homogênea dos acordos, inclusive aqueles que repercutem nas políticas de saúde. Existem ainda organismos consultivos integrados por representantes de segmentos sócioeconômicos e da sociedade civil, o Comitê Econômico e Social Europeu e o Comitê das Regiões, este último com representantes governamentais regionais e locais. As instituições fi- nanceiras européias são o Banco Central Europeu responsável pela gestão do Euro e da política monetária da União, e o Banco Europeu de Investimentos que financia projetos de desenvolvimento. Por fim, um Promotor de Justiça eleito pelo Parlamento Europeu acolhe queixas quanto à administração das instituições européias 18.

A União Européia representa longo processo histórico de transferência de competências nacionais para o nível supranacional, mediante cooperação e integração econômica. Significa união de esforços para conceber a integração regional com exercício de soberania dividida em que primam estratégias de cooperação (práticas intergovernamentais e tomada de decisão consensual) e estratégias de integração (práticas supranacionais e tomada de decisão por maioria). A consolidação européia afirma a integração como alternativa viável de redução de diferenças regionais, na qual a noção de fronteira assume aspecto mais permeável 22 . Nesse sentido, ao tornar-se Estado-Membro, cada país transfere determinadas competências e prerrogativas para organismos supranacionais, reduzindo a própria soberania. “A soberania ainda que fortemente enraizada no Estado-nação começa a migrar (...) rumo ao aparelho transnacional" 22 (p. 166). Essa transposição é típica dos processos de integração regional que para se efetivarem necessitam de criar foros multilaterais de harmonização, de apoio à superação de conflitos e promotores de acordos 23 .

\section{Uma Constituição para a Europa}

A União Européia está expressa em quase 100 mil páginas de acordos que fundamentam a integração. A recente Constituição Européia sintetiza esta regulamentação para substituir o conjunto de Tratados 24, consolida o conjunto de direitos cívicos, políticos, econômicos e sociais; trata da repartição de competências entre a União e os Estados-Membros, das tarefas das instituições, da eficácia externa e da legitimidade da União 18. A sua adoção marcará novo passo na construção do Estado supranacional, confirmando a expansão e a integração, com adequações institucionais para receber novos países e continuar assistindo regiões e grupos sociais em dificuldades 25 .

O Tratado que institui uma Constituição para a Europa, assinado em outubro de 2004, para entrar em vigor deve ser adotado após consulta pela via parlamentar e/ou por referendo em todos os Estados-Membros até outubro de 2006. Por mais que dez países já tenham ratificado o documento, a adoção do Tratado Cons- 
titucional permanece em debate por conta das controvérsias quanto ao caráter social do texto em decorrência dos resultados recentes de "não à Constituição", na França e na Holanda.

\section{A formação do mercado único europeu e repercussões sobre as políticas de saúde}

Os países da União Européia têm tradição na garantia de proteção social, caracterizando-se como amplos sistemas de bem-estar que, embora se diferenciem quanto à organização dos sistemas de atenção à saúde, guardam em comum o caráter público, a solidariedade social e a cobertura universal 20 . Os modelos de atenção variam entre dois tipos, com predomínio do primeiro: bismarkiano - seguro social financiado por contribuições do empregador e do trabalhador -, e beveridgiano - sistema nacional de saúde financiado com recursos fiscais. Princípios de justiça social são compartilhados entre os Estados-Membros e se expressam em diversas diretivas dos Tratados, afirmativas de compromisso com a proteção social. Entretanto, devido ao reconhecimento das heterogeneidades internas e históricas de configuração dos sistemas de saúde na União Européia, a garantia de proteção social à saúde permanece responsabilidade de cada EstadoMembro. Entre 1958 a 1998, contudo, 233 regulamentos da União Européia afetaram os serviços de saúde 20. As repercussões da integração européia na saúde são aqui analisadas nos Tratados, no tocante às ações de saúde pública, e nos sistemas nacionais de saúde quanto à regulamentação da livre circulação.

\section{A saúde nos Tratados:} ações de saúde pública

O Tratado de Maastricht, que estabeleceu a estrutura política e econômica do mercado único europeu, teve importância para a saúde ao estabelecer que a organização e a prestação de serviços de saúde são responsabilidades dos Estados-Membros. Para assegurar alto nível de proteção à saúde no mercado comum com a livre circulação, o artigo 152 eleva a saúde pública ao caráter comunitário e define que a ação da Comunidade, que será complementar das políticas nacionais, incidirá na melhoria da saúde pública e na prevenção das doenças e afecções humanas e na redução das causas de perigo para a saúde humana 26 . A proteção à saúde como objetivo comunitário se manifestou em medidas de saúde pública cooperativas, subsi- diadas e complementares às ações dos Estados-Membros nos domínios da prevenção, investigação, informação e educação. O mesmo artigo reforçou o caráter de transversalidade da proteção da saúde a ser assegurada na definição e execução de todas as políticas e ações da Comunidade 26. A Constituição Européia, em processo de ratificação, mantém o disposto no Tratado da União Européia: reafirma o caráter comunitário complementar da saúde pública e a soberania nacional para a organização da assistência.

Em cumprimento ao acordado, na União Européia o domínio da saúde pública é atividade comunitária, institucionalizada em comissões, comitês, agências e programas específicos. A política comunitária de saúde pública está orientada para a melhoria da informação, resposta rápida às ameaças e abordagem de fatores determinantes, perpassando o ambiente, a educação e os tratamentos médicos seguros (medicamentos, tecnologias, sangue e órgãos). Para o período de 2003-2008, foi acordado o Programa Comunitário de Ação em Saúde que reforça a articulação entre políticas públicas, promove a participação social e estimula o trabalho em redes de informação, de regulação, de intercâmbios e de avaliação. A informação e consulta ampliada em saúde pública ocorre em Fórum de Saúde da União Européia 18.

Enquanto na saúde pública houve tendência para a harmonização, as políticas de atenção à saúde de cada Estado-Membro sofreram, por sua vez, efeitos complexos e diversos, intencionais e não intencionais com a unificação econômica frente às modalidades distintas de financiamento, de organização e de cobertura dos serviços de saúde $8,21,27,28$. O Tratado de Maastricht completa a formação do mercado único europeu com a livre circulação, a qual impõe ajustes macro-econômicos e gera novas dinâmicas com impactos nos sistemas de saúde dos Estados-Membros. Esses implicaram restrições importantes para a ação nas políticas sociais, já que gastos públicos em saúde e possíveis déficits dos seguros sociais influem no cumprimento ou não dos critérios econômicos acordados 29. Por outro lado, a regulamentação da livre circulação afeta as políticas de saúde em diversos âmbitos 7,19,20,30.

\section{Repercussões da livre circulação sobre as políticas de saúde}

A constituição do mercado único europeu se concretiza na garantia e no exercício da livre circulação de mercadorias, serviços, pessoas e capital entre os Estados-Membros. Na perspec- 
tiva do mercado, serviços, mercadorias e capital são objeto de regulação de modo a adaptálos às regras comunitárias, para que circulem como as pessoas livremente entre os EstadosMembros. A liberdade de circulação tem impactos específicos nos sistemas de saúde 19,21,31,32.

A livre circulação de pessoas tem repercussões mais significativas na saúde, seja quanto à garantia dos direitos sociais, seja quanto à oferta de profissionais de saúde 31 . No mercado de trabalho foram regulamentados o reconhecimento mútuo de diplomas e a adaptação de currículos para facilitar a mobilidade de profissionais de saúde. Pelo lado da demanda, os direitos sociais e de saúde de trabalhadores foram regulamentados para a coordenação de sistemas de previdência e cobertura de seguros, de maneira a facilitar a movimentação destes cidadãos e garantir o exercício de direitos adquiridos. A segurança, a saúde do trabalhador e as condições de trabalho são harmonizadas desde o início da União Européia de forma que não impeça a livre circulação de trabalhadores. O movimento de pessoas em busca de serviços de saúde em outro país foi feito pelo Regulamento CEE N. 1408/71, e é também objeto de jurisprudências da Corte de Justiça Européia, abordado em seguida.

A regulamentação da livre circulação de mercadorias na saúde afetou especialmente a distribuição e oferta de medicamentos, insumos e equipamentos, a assistência farmacêutica e aspectos da vigilância sanitária relacionados à fabricação e circulação de produtos. A política de equipamentos médicos passou a incluir processo de licitação internacional. A fim de regular a produção e distribuição de medicamentos foi criada a Agência Européia de Medicamentos com funções de registro, certificação e licenciamento. Foram firmados acordos comunitários para controle de substâncias perigosas e radioativas e padrões sanitários comuns para a circulação de produtos.

A livre circulação de serviços na saúde repercutiu notadamente sobre a oferta de seguros privados. Isso devido à decisão da Corte de Justiça Européia que não submeteu os seguros sociais aos ditames da livre circulação, pois estes se fundamentam em princípios de solidariedade e, portanto, se organizam por regulamentação nacional. Porém, o fato de prestadores privados poderem oferecer serviços de saúde em qualquer país poderá repercutir sobre a prestação ambulatorial e hospitalar dos Estados-Membros. A livre circulação de capitais exibe, por sua vez, efeitos sobre investimentos hospitalares, e pode vir a dificultar a regulação e o planejamento da oferta hospitalar em paí- ses onde estes serviços são predominantemente públicos.

A análise dessas repercussões tem demonstrado que intervenções em direção ao mercado único europeu resultaram em efeitos nos sistemas de saúde 28. A mobilidade de profissionais de saúde, a licença e o acesso para os fármacos, o sistema de saúde para turistas, o sistema de cobertura para trabalhadores migrantes resultam de impactos intencionais e não intencionais da integração. Efeitos não intencionais se manifestam na compra, provisão e entrega dos serviços de saúde e resultam, em parte, da insuficiente abordagem que tiveram os serviços de saúde quando do desenho de diretrizes e regulamentações do mercado 7,8,19,33. Os efeitos intencionais e não intencionais rebatem distintamente em cada Estado-Membro frente às diferentes modalidades de organização política dos sistemas e serviços nacionais de saúde e às características específicas, como organização administrativa e autonomia regional 20.

\section{Acesso às ações assistenciais na União Européia}

Na União Européia, apenas as ações de saúde pública são objeto de regulamentação comunitária, visto que os Tratados reservam ao Estado-Membro a responsabilidade pela organização da oferta de serviços de saúde. No entanto, a livre circulação de pessoas, inclusive trabalhadores, no interior do território europeu integrado gerou situações em que o acesso aos serviços de saúde em outro Estado-Membro passou a ser objeto de regulamentação específica, posteriormente ampliado por jurisprudências da Corte de Justiça Européia 31. Além disso, em regiões de fronteira desenvolvem-se projetos que buscam garantir cuidado integrado de saúde beneficiando-se dos avanços da integração econômica 34 .

\section{A regulamentação do acesso à saúde em outro Estado-Membro}

O acesso aos serviços de saúde em outro Estado-Membro foi regulamentado ainda nos anos 1970, para garantir aos trabalhadores migrantes direitos de seguridade social. Em 1971, a Comunidade Econômica Européia (CEE) emitiu o Regulamento CEE N. 1408/71 relativo à aplicação dos regimes de seguridade social aos trabalhadores e familiares que se deslocavam no interior do mercado. Posteriormente, qualquer pessoa durante estada temporária passou a ter direito a aceder aos cuidados de saúde 
imediatamente necessários, nas mesmas condições que os cidadãos nacionais 35,36 . Em seguida foi introduzido o deslocamento para tratamento pré-autorizado. Fundamentado nos objetivos de garantia dos direitos de proteção social, este Regulamento teve efeitos não intencionais entre os quais o de estender para fora do país a escolha do cidadão em consumir mercadorias e serviços médicos, além de autorizar a importação e exportação de serviços de saúde 28,31 .

Para instrumentar os direitos previstos no Regulamento CEE N. 1408/71 foram criados diferentes formulários, com a finalidade de atender variadas categorias de beneficiários - trabalhadores, turistas, estudantes - cujo acesso à assistência era distinto. Os formulários atendiam situações específicas como a prestação de assistência durante estada por motivos de trabalho (E106, usuário de duplo sistema), nos casos de turismo e viagens (E111, garante apenas emergências), na busca de emprego (E119), para estudantes e trabalhadores enviados a outro país (E128). O formulário E112 autoriza viagem para tratamento médico pré-definido por motivos específicos de falta ou dificuldade de prestação do serviço, tais como lista de espera, acesso às novas tecnologias, proximidade geográfica 37 . Em todos esses casos, os beneficiários devem portar o formulário respectivo ao buscarem o serviço no outro país, o que na prática nem sempre ocorre 38 .

A mobilidade de pacientes na União Européia sob o abrigo do Regulamento CEE $N$. 1408/71 tem pequeno impacto numérico e financeiro 31. Dados de 1998 demonstram que o fluxo de pacientes entre os Estados-Membros correspondeu a apenas $0,1 \%$ dos gastos públicos em saúde na União Européia (2 Euros per capita). O menor fluxo de pacientes (14\%) e o maior gasto $(60 \%)$ foi nos casos de cuidados previamente autorizados (E112). O maior fluxo de pacientes (53\%) foi de trabalhadores (E106) ajustado a $16 \%$ dos gastos. Os casos de curta estadia (E111) e atendimento em emergência corresponderam a $33 \%$ dos fluxos de pacientes e a $26 \%$ dos gastos.

Em dezembro de 2003, a União Européia aprovou novas recomendações sobre a mobilidade de pacientes que explicitam direitos e deveres destes e evidenciam a preocupação com a utilização de recursos e a partilha de capacidade nos cuidados transnacionais. Nesse sentido, instituem sistema para acompanhar mobilidade de profissionais de saúde e rede de centros de referência e de avaliação das tecnologias da saúde. Os Estados-Membros, por seu turno, se comprometeram a melhorar a infor- mação sobre cuidados transnacionais e a integração dos objetivos de saúde em todas as políticas. Em busca do desenvolvimento de visão européia comum dos sistemas de saúde, os Estados-Membros firmaram compromisso com mecanismos de cooperação em serviços e assistência 33.

Em 2004, entrou em circulação o cartão europeu de seguro de doença que substituirá gradualmente os formulários "E”, exceto o E112 (autorização de viagem para tratamento). O cartão não altera direitos ou obrigações regulamentados anteriormente, mas almeja eliminar obstáculos à mobilidade geográfica por motivo de turismo, busca de emprego e transferência de trabalho 39. Tem ainda função de simplificar o acesso, agilizar o reembolso e confirmar os direitos. Secundariamente, pode auxiliar o alinhamento de benefícios face às competências dos Estados-Membros na organização dos sistemas de saúde.

Frente à diversidade da organização, da cobertura e do financiamento dos sistemas nacionais de saúde esses diversos instrumentos têm utilidade para viabilizar e facilitar as relações entre os países, na garantia da prestação de serviços prevista em um país e a ser prestada nos termos do sistema de saúde de outro. A garantia do direito à saúde é reconhecida como fundamental para a livre circulação de pessoas no mercado europeu, de modo que não se constitua uma barreira não tarifária ao processo de integração 17 , ainda que o acesso aos serviços esteja disciplinado sob algumas condições.

\section{A interpretação do direito comunitário de acesso aos serviços de saúde}

Com o avanço do mercado único, os cidadãos europeus manifestam interesse em consumir produtos e serviços de saúde em outro EstadoMembro, como exercício da livre circulação. A interpretação desse direito tem sido objeto de jurisprudência pela Corte de Justiça Européia compatibilizando o Regulamento CEE N. 1408/71 às regras do mercado e reconhecendo a responsabilidade dos Estados-Membros na organização dos sistemas nacionais de saúde. As decisões da Corte na solução de controvérsias de direitos em saúde vêm influenciando a dimensão européia dos sistemas de saúde. Tais pronunciamentos causam repercussões distintas nos Estados-Membros; contudo, as possibilidades de acesso à saúde em outro país ficam ampliadas por essas decisões.

Os casos julgados pela Corte de Justiça Européia se referem às dúvidas de direitos de acesso aos serviços e produtos de saúde no merca- 
do único europeu 28,31. São casos de cidadãos que mediante argumento do exercício da livre circulação buscam em outro Estado-Membro serviços ou produtos de saúde e, posteriormente, recorrem à Corte para solicitar a garantia de reembolso destas despesas, realizadas sem a prévia autorização (E112). Os pronunciamentos da Corte de Justiça Européia em relação aos casos Kohll e Decker (1998) e Smits/Peerbooms e Vanbraekel (2001) perpassam questões da interpretação da extensão do direito ao acesso aos serviços e produtos de saúde no mercado único, bem como a livre circulação de pessoas e consumo de saúde 6 . Frente às distintas modalidades dos sistemas de saúde dos EstadosMembros, nos aspectos organizacionais e financeiros, as decisões da Corte repercutem de modo distinto no planejamento e na entrega destas ações 40 .

As decisões confirmam que pessoas têm liberdade de buscar serviços de saúde em outro Estado-Membro sob certas condições. Ao cidadão é garantido o direito ao reembolso, sem autorização prévia e com fundamento na livre circulação, correspondente aos valores gastos no outro Estado-Membro. $\mathrm{O}$ atendimento prestado, por sua vez, deve ser nas mesmas condições que ao cidadão residente e de acordo com a legislação do Estado-Membro onde foi realizado. Os Estados-Membros devem cumprir a regulação comunitária ao organizar os sistemas nacionais de saúde e ao criar esquemas de autorizações prévias. Restrições devem estar amparadas por justificativas de manutenção de equilíbrio financeiro setorial. Em caso de recusa da autorização prévia (E112), a disponibilidade de tratamento igual ou equivalente sem espera, deve ser garantida 28,40 .

As jurisprudências da Corte foram tornando claro para os Estados-Membros que mecanismos do mercado único se aplicam ao setor saúde independentemente da forma de organização deste. E para a União Européia que qualquer discussão futura do mercado de serviços de saúde há que considerar os arranjos da seguridade social dos Estados-Membros. Embora seja reconhecido que os sistemas nacionais observam e adaptam sistemáticas às regras da Corte de Justiça Européia e do mercado único, a situação desejada não é a garantia de escolha máxima pelo cidadão, como consumidor de serviços de saúde, pois isso comprometeria o planejamento e a organização dos serviços e ações de saúde nacionais 19,27,30,31.

As repercussões das jurisprudências da Corte nas políticas de saúde provocaram intensivos debates e geraram controvérsias nos domínios financeiro, organizacional e de acesso. Há posicionamentos de que fundamentar decisões sobre acesso à saúde no imperativo do mercado prioriza a lógica individual do consumo em detrimento da coletiva de proteção social a ser garantida pelo Estado 19,20. Existe a preocupação da conformação de cesta européia virtual de cuidados de saúde 41 , com impacto variável na composição interna do sistema de cada país ${ }^{42}$. Atualmente, policy makers europeus reconhecem a contribuição destas jurisprudências na transparência do direito à saúde, nas possibilidades de acesso em outro Estado-Membro de serviços não disponíveis 41 e no consenso de que nenhum sistema nacional de saúde está isento das obrigações acordadas e regulamentadas 43 . Na perspectiva territorial, as jurisprudências fortalecem o esforço comunitário de romper fronteiras, garantir a aplicação do direito em outro Estado-Membro e resguardar a soberania da responsabilidade pelos cuidados de saúde a cada país 41 .

\section{Cuidados integrados entre países e nas regiões de fronteira}

Embora os registros sejam insuficientes e o impacto financeiro pequeno, o fluxo de pacientes entre países na União Européia concentra-se nas fronteiras 31 . Nessas regiões, o movimento de trabalhadores é intenso e há pressão em busca de cuidados de saúde 44 . Nas fronteiras internas da União Européia se manifesta contradição importante para o acesso aos serviços de saúde: integração de espaços territoriais vis a vis sistemas de saúde limitados ao território do país 6 . Nas fronteiras a garantia de acesso aos serviços de saúde é importante para que disparidades territoriais e dos sistemas de saúde não representem obstáculos não tarifários à integração e à coesão econômica e social 17. Fronteiras são territórios vinculados à identidade nacional que se dilui, em que se manifestam situações de dubiedade - diferença versus integração -, em que, além de contrastes de língua e de cultura, dá-se convivência cotidiana entre sistemas políticos, monetários, de segurança, de proteção social distintos, fato que gera tensões e evidencia contradições entre as realidades local, regional e do conjunto de instituições, normas e políticas 45 .

A partir do Tratado de Maastricht foram desenvolvidos projetos estruturais com atividades dirigidas para as fronteiras européias 46 . Em 1994, foi criado o Comitê das Regiões, órgão consultivo integrado por representantes dos poderes locais e regionais que subsidia nas fronteiras a aplicação da legislação européia nos domínios da saúde, educação, cultura, política 
de emprego, política social, ambiente, formação profissional e transportes 31 .

A revisão de projetos de cooperação e assistência em saúde entre regiões ou EstadosMembros, vários destes localizados nas fronteiras, demonstra que objetivam melhorar possibilidades de acesso e ampliar serviços ofertados. Além disso, facilitar relações entre agências governamentais e prestadores de serviços e solucionar tensões entre direitos do paciente e regras de autorização. As principais ações de cooperação são em emergências (ambulâncias, equipes de resgate, equipamentos), assistência (serviços complementares), telemedicina (consulta, diagnóstico, compartilhamento de dados e troca de experiência), compra e utilização de equipamentos, pesquisa, recursos humanos, rede de boas práticas, e estabelecimento de estruturas comuns 34 .

Mesmo que essas experiências apresentem grande diversidade de ações, exibem motivações e resultados bastante semelhantes. Os projetos predominantes buscam atender problemas de capacidade e de escala de serviços especializados, e vinculam-se aos hospitais universitários. Muitos envolvem localidades de países onde os julgamentos da Corte de Justiça Européia tiveram maiores repercussões (Bélgica, Holanda, Alemanha) e buscam auxiliar o controle de custos e do atendimento 34 .

O fluxo de pacientes entre países relacionase a fatores de ordem pessoal, social, financeiro, clínico, gerencial e político. Para os pacientes os fatores mais importantes são o tempo de espera, nível de cuidado, distância, amizades ou parentescos. Enquanto que para os profissionais de saúde contatos com o sistema do outro país e a falta de recursos locais são fatores mais mencionados para encaminhar paciente a outro país. Tanto para os pacientes quanto para os profissionais as barreiras mais evidentes para a busca de serviços de saúde em outro país são a língua, a cultura, aspectos legais e administrativos. Entretanto, nas regiões com projetos mais organizados observou-se tendência para o aumento de fluxo 34 .

\section{Considerações finais}

A construção da União Européia tem fundamentos econômicos, entretanto, ilustra processo gradual de aprofundamento e alargamento que almeja a transição da Europa econômica para a Europa política com a adoção da Constituição Européia, cujos valores devem influenciar todas as políticas. A saúde teve papel menor na integração, ainda que desde os primei- ros acordos a garantia e a proteção da saúde e a segurança do trabalhador tenham sido objetos de regulamentação. A partir de 1993, a saúde é incluída na agenda como tema específico, mediante ações comunitárias de saúde pública. Embora a responsabilidade pela organização dos serviços de saúde seja de cada EstadoMembro, princípios de proteção social compartilhados garantem ao cidadão acesso regulado à saúde em outro Estado-Membro. À medida que avança a consolidação da livre circulação, os Estados-Membros reconhecem efeitos do mercado único nas políticas de saúde. Os resultados acumulados pela União Européia evidenciam que processos de integração são exercícios de conciliação de interesses e que embora o fator motivador seja o econômico, as repercussões que causam na saúde impõem interação entre as políticas econômicas e sanitárias.

A revisão de literatura mostra que a integração européia repercutiu sobre os sistemas nacionais de saúde não tanto por legislação específica, mas como conseqüência dos esforços de implementação do mercado único europeu, nos aspectos econômicos e da livre circulação. A garantia do acesso aos serviços e produtos de saúde no interior do mercado europeu foi utilizada para romper barreiras de circulação. Na modalidade de integração assumida, a queda de barreiras à circulação de pessoas, produtos, serviços e capital significou na saúde a livre movimentação de profissionais, pacientes, trabalhadores, fármacos, tecnologias e serviços. Na saúde, a livre circulação de pessoas teve maior impacto sobre a oferta de profissionais e na demanda de migrantes pela garantia de acesso. Acordos comunitários buscaram tanto regular o mercado de trabalho para facilitar o reconhecimento de profissões quanto a compensação financeira entre os sistemas para a garantia de direitos. Por sua vez, projetos em desenvolvimento nas regiões fronteiriças da União Européia, motivados pela integração, exibem melhoria da capacidade de garantir cuidados integrais de saúde mediante articulação de serviços, formação conjunta de profissionais e novos arranjos organizacionais.

Embora as repercussões da legislação comunitária tenham afetado os Estados-Membros independentemente do modelo de política de saúde adotado, os impactos foram distintos frente às características de organização e financiamento de cada sistema nacional de saúde. Nesse sentido, a integração européia repercutiu de modo intencional e não intencional nas políticas de saúde, em aspectos de regulação, financiamento, oferta, acesso e distribuição de serviços em cada Estado-Membro. Os 
efeitos intencionais resultaram em acordos no domínio da saúde pública, facilitação da mobilidade de profissionais, regulamentação para aquisição pública de mercadorias e serviços de saúde, sistema comum para licenciamento, produção e distribuição de fármacos e insumos médicos, e sistemáticas para garantir a cobertura e acesso aos serviços de saúde no interior da Comunidade. Os efeitos não intencionais são derivados de metas econômicas comunitárias e, em parte, resultam da insuficiente abordagem da saúde na regulamentação do mercado único, gerando impactos na compra, provisão e entrega dos serviços de saúde. Para construir o mercado único europeu, foram impostos critérios e metas econômicas aos Estados-Membros com o objetivo de garantir a estabilidade econômica. Os Estados-Membros frente às regras acordadas têm de realizar adaptações internas para cumpri-las, confrontando objetivos sociais com os de mercado e, em decorrência, as políticas sociais e de saúde terminam por subordinar-se aos imperativos das políticas econômicas. Assim, na integração européia permaneceu tensão não resolvida entre os objetivos do mercado único e as políticas nacionais de saúde.

Entre MERCOSUL e União Européia existem semelhanças e diferenças. Na atualidade, o MERCOSUL se conforma como união alfandegária, entretanto, objetiva alcançar a livre circulação de pessoas, produtos, serviços e capitais. Mesmo em nível de integração anterior ao da União Européia, a reflexão sobre esta antecipa desafios a enfrentar na consolidação do bloco do cone sul que ao caminhar para o mercado comum tem como exemplo bem sucedido a União Européia. Assim, o ponto fundamental de simetria entre ambos é alcançar a integração regional, conquanto o histórico de relações e heterogeneidades entre os integrantes, além de aspectos jurídicos sejam diferenças entre os dois blocos.

Na saúde, a União Européia reforçou objetivos comuns de combinar solidariedade com sustentabilidade financeira, de introduzir diretrizes de mercado mantendo o papel de responsabilidade do Estado-Membro. Embora a titularidade do direito à saúde permaneça ligada à nacionalidade, os Estados-Membros adotaram inovações na organização e produção de serviços para a garantia do acesso em outro país. No MERCOSUL, os Estados-Membros possuem distintos desenhos de políticas de saúde tanto nos aspectos organizacionais e financeiros quanto de cobertura. Ainda que exista contigüidade no território epidemiológico e sanitário para além das fronteiras, os países têm perfis populacionais, de infra-estrutura e de responsabilidades sanitárias variados.

É reconhecido que a saúde é política pública resultante de consensos sócio-políticos em cada país. Nesse sentido, as variações significativas entre desenhos dos sistemas e das políticas dos Estados-Membros no MERCOSUL denotam que há pouco consenso regional sobre o escopo da proteção social, diferentemente do observado na União Européia. O Brasil vem consolidando sistema de saúde público, de base universal, descentralizado e com participação social e têm atraído atenção e interesse de outros governos. Embora longe de uma ação de regulação dos serviços de saúde para a integração regional, essa situação favorece acordos de cooperação e oferece paradigmas para a harmonização no campo da saúde no MERCOSUL.

Na União Européia a saúde foi subordinada ao processo de integração e a garantia do direito de acesso no mercado interno foi uma forma de evitar barreiras não tarifárias à livre circulação, assim como a ação comunitária de saúde pública. O MERCOSUL segue trilha semelhante ao realizar a inclusão gradual e incipiente de questões de vigilância sanitárias e epidemiológicas, relacionadas à circulação de produtos e às ações de saúde pública de alta externalidade. Essa discussão ocorre em subgrupo de trabalho específico (SGT-11) que busca harmonização normativa entre Estados-Partes.

Traçando paralelos com a União Européia, em um cenário futuro do MERCOSUL no qual a integração se aprofunda, as diversidades das políticas de saúde devem ser superadas para garantir o direito ao acesso em outro país de modo que a ausência de acesso não se configure como barreira à livre circulação das pessoas no interior do Bloco. Nesse sentido, EstadosPartes acordariam regras e mecanismos de garantia desse acesso e implantariam instrumentos intergovernamentais à semelhança dos formulários "E” ou o Cartão de Saúde MERCOSUL. Em etapa intermediária, a adoção de procedimentos de troca de serviços, em ações cooperativas locais de fronteira com apoio dos governos nacionais, pode contribuir para a integração regional. Considerando a experiência européia, a opção menos indicada é a restrição de acesso, que em processos de integração regional se configura como barreira não-tarifária. Além disso, no caso do SUS o não atendimento pode comprometer princípios constitucionais, considerando a mobilidade histórica de famílias nas fronteiras.

As garantias dos direitos sociais são fatores importantes em processos de integração como demonstra a União Européia. A problemática 
do acesso aos serviços de saúde no MERCOSUL, contudo, não é de simples abordagem seja no aspecto institucional seja no político. Avançar na reflexão das repercussões da integração regional sobre os sistemas de serviços de saúde a partir das regiões de fronteiras pode contribuir para antecipar questões na plena vigência do MERCOSUL.

\section{Resumo}

Com base em revisão, o artigo explora repercussões nas políticas de saúde da integração regional entre países na União Européia. O objetivo é revisar a regulação do acesso em outro país, com a efetivação do mercado único e da livre circulação (de pessoas, produtos, serviços e capital). Inicia-se com revisão de modalidades de integração e descreve-se o alargamento e a institucionalização de organismos comunitários. As repercussões da integração européia nas políticas e na regulamentação do acesso à saúde foram analisadas. Impactos do mercado na saúde resultam de diretivas dos Tratados e de ajustes de políticas decorrentes da livre circulação. O acesso às ações assistenciais é regulamentado gradualmente e garantido por jurisprudências. Projetos nas fronteiras ilustram dinâmicas em que disparidades são utilizadas a favor do cuidado integral. Na mais antiga experiência de integração, a regulamentação do mercado gerou impactos intencionais e não intencionais nas políticas de saúde dos Estados-Membros, independentemente do modelo de organização. O conhecimento e a análise desta trajetória sinaliza desafios ao MERCOSUL e contribui para o debate e decisões futuras.

Blocos Econômicos; Política de Saúde; Saúde em Fronteira; União Européia

\section{Colaboradores}

L. Guimarães e L. Giovanella compartilham a autoria do artigo na concepção, estrutura, busca de fontes de referência e análise para a construção do texto, e na aprovação final para a publicação. L. Guimarães preparou a primeira versão do texto que foi sendo revisado e elaborado conjuntamente pelas duas autoras em seguida.

\section{Agradecimentos}

L. Guimarães é bolsista do Conselho Nacional de Desenvolvimento Científico e Tecnológico. 


\section{Referências}

1. Bambas A, Casas JA, Drayton HA, Valdés A. Health and human development in the new global economy - the contributions and perspectives of civil society in the Americas. Washington DC: Pan American Health Organization; 2000.

2. Organización Mundial de la Salud/Organización Mundial del Comercio. Los acuerdos de la OMC y la salud pública: un estudio conjunto de la OMS y la Secretaria de la OMC, 2002. http://whqlibdoc. who.int/hq/2002/a76863.pdf (acessado em 18/ Abr/2005).

3. Godue C. La salud en los procesos de globalización y de internacionalización. In: Ahumada C, Hernández A, Velasco M, editores. Relaciones internacionales, política social y salud: desafíos en la era de la globalización. Relaciones internacionales, política social y salud: desafíos en la era de la globalización. Santa Fe de Bogotá: Relaciones internacionales, política social y salud: desafíos en la era de la globalización; 1998. p. 2545.

4. Altvater E, Mahnkopf B. Grenzen der globalisierung. Münster: Verlag Westfälisches Dampfboot; 1996.

5. Bolis M, editor. Acceso a los servicios de salud en el marco del TLC. Washington DC: Organización Panamericana de la Salud; 1999.

6. Wismar M, Busse R, Berman P. The Europe Union and health services. The context. In: Busse R, Wismar M, Berman PC, editors. The European Union and health services. The impact of the single European market on member states. Amsterdam: IOS Press; 2002. p. 17-29.

7. Busse R, Wismar M, Berman PC, editors. The European Union and health services. The impact of the single European market on member states. Amsterdam: IOS Press; 2002.

8. Leidl R. Introduction. In: Leidl R, editor. Health care and its financing in the single European market. Biomedical and health research. Amsterdam: IOS Press; 1998. p. 3-10.

9. Barcellos C, Peiter P, Rojas LI, Matida A. A geografia da AIDS nas fronteiras do Brasil. http:// www.igeo.ufrj.br/fronteiras/pesquisa/fronteira/ p02pub03.htm (acessado em 28/Mar/2005).

10. Silva LIL, Amorim C, Guimarães SP. 1o de janeiro de 2003, Discurso do Senhor Presidente da República, Luiz Inácio Lula da Silva, na Sessão de Posse, no Congresso Nacional, em Brasília. In: Instituto de Pesquisa de Relações Internacionais, organizador. A política externa no Brasil. Brasília: Instituto de Pesquisa de Relações Internacionais; 2003. p. 25-46. (Coleção Países e Regiões).

11. Simionatto I, Nogueira VMR, organizadoras. Dilemas do Mercosul: reforma do Estado, direito à saúde e perspectivas da agenda social. Florianópolis: Lago Editora; 2004.

12. Lucchese G. Globalização e regulação sanitária: os rumos da vigilância sanitária no Brasil [Tese de Doutorado]. Rio de Janeiro: Escola Nacional de Saúde Pública; Fundação Oswaldo Cruz; 2001.

13. Basso M. Integração econômica e institucionalização: as experiências do Mercosul e da União Européia. Revista CEJ 1998; 2:72-83.
14. Chavez CH. Argentina y Mercosur. Colección de documentos Institut Internacional de Governabilitat de Catalunya. http://www.iigov.org/documentos/?=4_0127 (acessado em Dez/2003).

15. Ventura DFL. As assimetrias entre o Mercosul e a União Européia: os desafios de uma associação inter-regional. Barueri: Editora Manole; 2003.

16. Threlfall M. European social integration: harmonization, convergence and single social areas. J Eur Soc Policy 2003; 13:121-39.

17. Theofilatou M, Maarse H. European Community harmonization and spillovers into health regulations. In: Leidl R, editor. Health care and its financing in the single European market. Biomedical and health research. Amsterdam: IOS Press; 1998. p. 13-37.

18. União Européia. A Europa em 12 lições. http:// europa.eu.int/index_pt.htm (acessado em 07/Fev/ 2005).

19. Health \& Consumer Protection Directorate-General, European Commission. The internal market and health services: report of the high level committee on health. http://europa.eu.int/comm/ health/ph_overview/Documents/key06_en.pdf (acessado em 07/Fev/2005).

20. Mossialos E, McKee M, Palm W, Karl B, Marhold F. The influence of EU law on the social character of health care systems in the European Union. Repport submitted to the Belgian Presidency of the European Union - Final Version, Brussels. http:// www.ose.be/health/files/summary.pdf (acessado em 19/Nov/2001).

21. Wismar M, Busse R. Analysis of SEM legislation and jurisdiction. In: Busse R, Wismar M, Berman PC, organizadores. The European Union and health services. The impact of the single European market on member states. Amsterdam: IOS Press; 2002. p. 41-8.

22. Medeiros MA. Prerrogativas estatais, integração regional e lógica redistributiva. Lua Nova 2003; (58):141-68.

23. Draibe SM. Mercosur: la temática social de la integración desde la perspectiva institucional. Centro de Información para la Integración Regional del Uruguay, 1997-8. http://www.top.org.ar/publicac.htm (acessado em Set/2003).

24. Krätschell H, Renner, G. Weg zur EU-Motive, Interessen, Entescheidungen. Informationen zur Politische Bildung 2002; (213):4-12.

25. Stuart AM. UE um laboratório de políticas públicas. Teoria e Debate 2004; (60):48-53.

26. União Européia. Tratado da União Européia, versão compilada dos Tratados de Maastricht, de Amsterdã e de Nice em vigor a partir do ano de 2003. http://europa.eu.int/eur-lex/pri/pt/oj/dat/ 2002/c_325/c_32520021224pt00010184.pdf (acessado em 07/Fev/2005).

27. Paton C, Berman PC, Busse R, Ong BN, Rehnberg C, Renck B, et al. The Europe union and health services: summary. In: Busse R, Wismar M, Berman PC, editors. The European Union and health services. The impact of the single European market on member states. Amsterdam: IOS Press; 2002. p. 1-13. 
28. Wismar M, Gobrecht J, Busse R. Consumer choice of medical goods across borders. In: Busse R, Wismar M, Berman PC, editors. The European Union and health services. The impact of the single European market on member states. Amsterdam: IOS Press; 2002. p. 213-30.

29. De Vos PD, Dewitte H, Stuyft PVD. Unhealthy European health policy. Int J Health Serv 2004; 34:255-69.

30. Commission of the European Communities. Report on the application of internal market rules to health services. Implementation by the members States of the Court's Jurisprudence. http:// europa.eu.int/comm/health/ph_information/im plement/wp/systems/docs/ev_20040325_rd01_e n.pdf (acessado em 07/Fev/2005).

31. Busse R, Drews M, Wismar M. Consumer choice of healthcare services across borders. In: Busse R, Wismar M, Berman PC, editors. The European Union and health services. The impact of the single European market on member states. Amsterdam: IOS Press; 2002. p. 231-48.

32. Schmucker R. Europäischer Binnenmarkt und nationale Gesundheitspolitik. Zu den Auswirkungen der vier Freiheiten auf die Gesundheitssysteme der EU-Mitgliedsländer. Jahrbuch für Kritische Medizin 2003; (38):107-20.

33. Comissão das Comunidades Européias. Acompanhamento do processo de reflexão de alto nível sobre a mobilidade dos doentes e a evolução dos cuidados de saúde na União Européia. http://europa.eu.int/eur-lex/pt/com/cnc/2004/com 2004_0301pt01.pdf (acessado em 07/Fev/2005).

34. Hermans LLMB, Brouwer W. Quality issues on cross-border care: a literature search, 2003. http:// www.ehma.org/Quality_Issues_on_Crossborder_Care.pdf (acessado em 07/Fev/2005).

35. União Européia. Regulamento CEE N. 1408/71, de 14 de Junho de 1971, relativo à aplicação dos regimes de segurança social aos trabalhadores assalariados e aos membros da sua família que se deslocam no interior da Comunidade. http://europa.eu.int/smartapi/cgi/sga_doc?smartapi!celexplus!prod!CELEXnumdoc \&lg=pt\&numdoc=31971R1408 (acessado em 07/Fev/2005).
36. Hermans HEGM, Berman PC. Access to health care and health services in the European Union: Regulation 1408/71 and the E111 Process. In: Lei$\mathrm{dl} \mathrm{R}$, editor. Health care and its financing in the single European market. Biomedical and health research. Amsterdam: IOS Press; 1998. p. 324-43.

37. Health Service Executive. Summary of forms used in relation to entitlements to health services under EU Regulations. http://www.nehb.ie/nehb/ services/eu.htm (acessado em 07/Fev/2005).

38. Avilés NR, Villamil FS, Rodríguez MAP. The mobility of citizens. A case study and scenario on the health services of the Costa del Sol. In: Busse R, Wismar M, Berman PC, organizadores. The European Union and health services. The impact of the single European market on member states. Amsterdam: IOS Press; 2002. p. 97-108.

39. União Européia. Cartão Europeu de Seguro Doença. http://europa.eu.int/scadplus/leg/pt/ cha/c10619.htm (acessado em 07/Fev/2005).

40. Busse R, Wismar M. Scenario on the development of consumer choice for healthcare services. In: Busse R, Wismar M, Berman PC, organizadores. The European Union and health services. The impact of the single European market on member states. Amsterdam: IOS Press; 2002. p. 249-58.

41. Nickless J. Smiths/Peerbooms: clarification of Kohll and Decker? Eurohealth 2001; 7:7-10.

42. Wismar M. ECJ in the driving seat on health policy but what's the destination? Eurohealth 2001; 7:5-6.

43. Byrne D. Public health in the European Union: breaking down barriers. Eurohealth 2001; 7:2-4.

44. Coheur A. Integrating care in the border regions an analysis of the Euregio projects. Eurohealth 2001; 7:10-12.

45. Ciccolella PJ. O capitalismo histérico: entre o protecionismo e a integração em blocos econômicos. In: Lavinas L, Carleial LMF, Nabuco MR, organizadores. Integração, região e regionalismo. Rio de Janeiro: Bertrand Brasil; 1994:43-53.

46. União Européia. Política regional: introdução. http://europa.eu.int/scadplus/leg/pt/lvb/g2400 0.htm (acessado em 07/Fev/2005).

Recebido em 09/Ago/2005

Aprovado em 10/Mar/2006 